
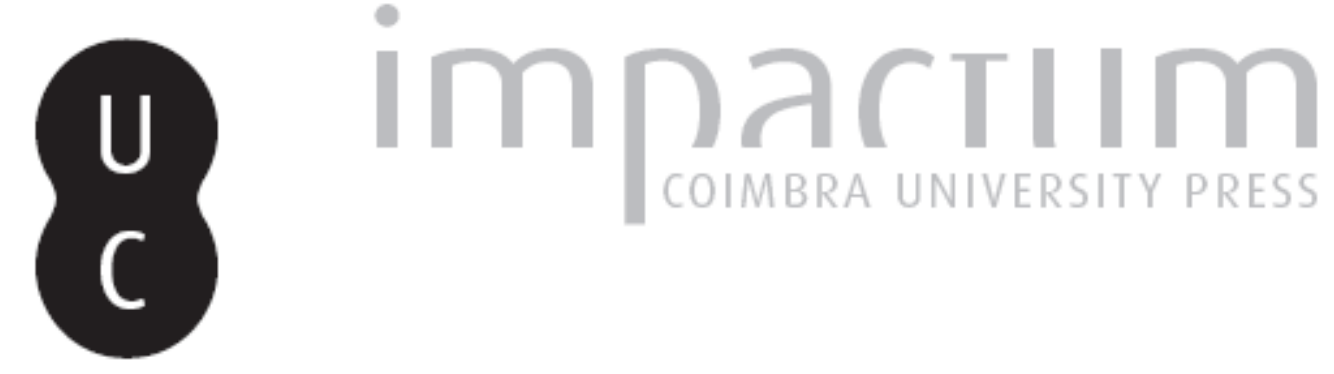

\title{
[Recensão a] Giuseppe Carlo Rossi. Lusitanista (1908-1983). Atti del Convegno Internazionale nel centenario della nascita (Napoli, 31 ottobre 2008-UNIOR; Lisbona, 3 dicembre 2008-I.I.C., organizzazione di Maria Luisa Cusati), a cura di Teresa Gil Mendes
}
Autor(es):
Simões, Manuel G.
Publicado por: Imprensa da Universidade de Coimbra
URL persistente:
URI:http://hdl.handle.net/10316.2/42437
DOI:
DOI:https://doi.org/10.14195/0870-8584_8_12

Accessed :

26-Apr-2023 14:35:19

A navegação consulta e descarregamento dos títulos inseridos nas Bibliotecas Digitais UC Digitalis, UC Pombalina e UC Impactum, pressupõem a aceitação plena e sem reservas dos Termos e Condições de Uso destas Bibliotecas Digitais, disponíveis em https://digitalis.uc.pt/pt-pt/termos.

Conforme exposto nos referidos Termos e Condições de Uso, o descarregamento de títulos de acesso restrito requer uma licença válida de autorização devendo o utilizador aceder ao(s) documento(s) a partir de um endereço de IP da instituição detentora da supramencionada licença.

Ao utilizador é apenas permitido o descarregamento para uso pessoal, pelo que o emprego do(s) título(s) descarregado(s) para outro fim, designadamente comercial, carece de autorização do respetivo autor ou editor da obra.

Na medida em que todas as obras da UC Digitalis se encontram protegidas pelo Código do Direito de Autor e Direitos Conexos e demais legislação aplicável, toda a cópia, parcial ou total, deste documento, nos casos em que é legalmente admitida, deverá conter ou fazer-se acompanhar por este aviso.

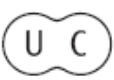




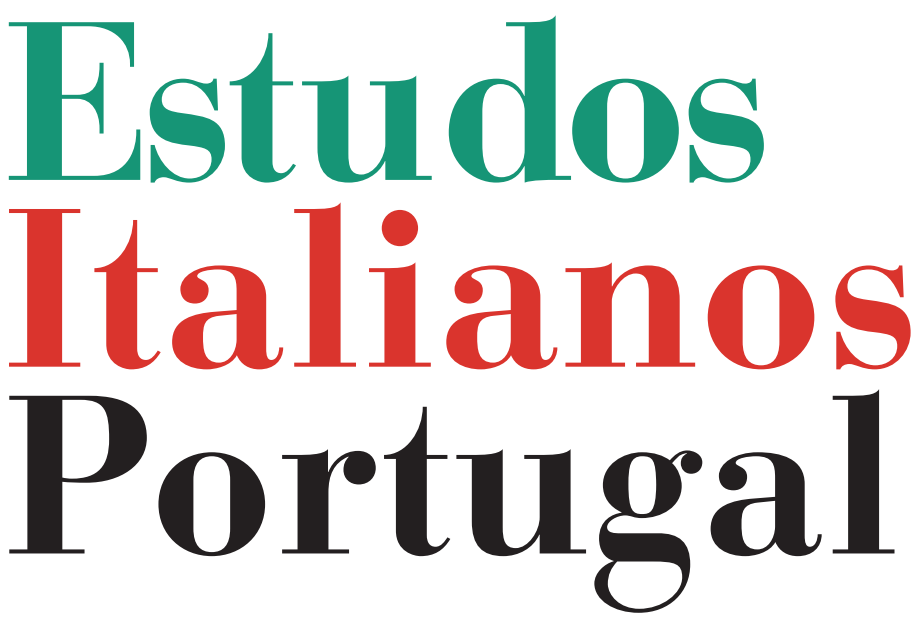

Instituto

Italiano

de Cultura

de Lisboa

Nova Série

$\mathbf{N}^{\circ} \mathbf{8}$ 
Giuseppe Carlo Rossi. Lusitanista (1908-1983). Atti del Convegno Internazionale nel centenario della nascita (Napoli, 31 ottobre 2008-UNIOR; Lisbona, 3 dicembre 2008-I.I.C., organizzazione di Maria Luisa Cusati), a cura di Teresa Gil Mendes, Roma, Albatros, 2012.

Por ocasião do centenário do nascimento de Giuseppe Carlo Rossi, o primeiro professor catedrático de Língua e literatura portuguesas em Itália, como se sabe, quis um grupo de estudiosos prestar-lhe a homenagem talvez mais válida culturalmente, organizando dois colóquios unificados pela revisitação da sua obra gigantesca. Da dimensão deste legado científico é-nos fornecida memória rigorosa na bibliografia organizada por Rosaria De Marco, com base nos elementos já precedentemente coligidos por Gerardo Grossi, Annamaria Pagliaro e Claudio Bagnati, isto é: 18 volumes de ensaios de crítica e de história literária; 54 ensaios publicados em volumes miscelâneos; 609 artigos inseridos em quotidianos e em revistas especializadas italianas e estrangeiras; 409 recensôes; 6 introduções a volumes diversos; 4 traduçôes (de que destaco a tradução portuguesa de Navegaçôes de Luis de Cadamosto e a tradução italiana de Volfrâmio, de Aquilino Ribeiro), para além de 202 verbetes para enciclopédias, histórias literárias, antologias, etc.. Dos dois colóquios - o de Nápoles e o de Lisboa - se reúnem aqui as várias comunicações com organização cuidada de Teresa Gil Mendes.

As "Actas" estão substancialmente divididas em três secçõos: "Studi sulla biografia", "Testimo- 
nianze" e "Interventi". Da primeira é justo referir a intervenção de Maria Luisa Cusati (pp. 20-29), organizadora do convénio, a qual recorda o percurso do estudioso e a sua actividade fundamental para a institucionalização dos estudos portugueses em Itália, favorecendo sempre as relaçôes culturais numa perspectiva de reciprocidade; e o trabalho de Laura Melania Rocchi (pp. 30-44), com base em documentos do Arquivo Histórico do "Ministero degli Esteri", onde se observa, com minúcia, o empenho didáctico e científico dos anos portugueses (1939-1948), sem esquecer a colaboração entusiástica na revista Estudos Italianos em Portugal, logo a partir do n. ${ }^{\circ} 2$, em 1940.

A segunda secção agrupa três testemunhos de outros tantos discípulos - Franco Tamassia, Gian Carlo Menichelli e Claudio Bagnati -, os quais recordam o magistério de Giuseppe Carlo Rossi e o seu entusiasmo como divulgador das culturas da área iberística. Mas é a terceira secção ("Interventi”) a parte mais nutrida e certamente mais original das "Actas", até porque, em linhas gerais, os textos aqui transcritos vão para além da simples homenagem e comemora- ção de uma figura, oferecendo-nos estudos críticos aprofundados sobre temas e problemas da sua obra monumental. Assim, Mariagrazia Russo (pp. 70-83) analisa o conhecido ensaio Il Leopardi e il mondo di lingua portoghese, publicado em 1970, do qual se parte para um trabalho posterior da própria estudiosa, clarificando questôes, já então levantadas, sobre a presença do poeta de Recanati na obra de António Feliciano de Castilho, de Antero de Quental ou de Fernando Pessoa.

Por seu lado Rita Marnoto (pp. 84-95) dedica a sua intervenção à análise do volume La letteratura italiana e le letterature di lingua portoghese, de 1967, e que conheceu uma versão revista e actualizada, em tradução portuguesa de Giuseppe Mea (1973). Saliente-se, entre outros motivos de inegável interesse, as pertinentes reflexôes desta estudiosa sobre as linhas de força de uma obra, em especial quando analisa as homologias entre o lusotropicalismo de Gilberto Freyre e as posiçōes de G.C. Rossi: "In comune, l'idea di una piattaforma tra il Portogallo e il Brasile, che Gilberto Freyre identifica nel lusotropicalismo e Giuseppe Carlo Rossi nella lingua portoghese” (p. 
95). Rita Marnoto entrevê, ainda, limites de informação em vários pontos do volume, "desvelados" por trabalhos posteriores de outros estudiosos, embora considere, e muito justamente, que até hoje não existe uma obra semelhante noutras literaturas estrangeiras $\mathrm{e}$ que tenham estabelecido um diálogo íntimo com as literaturas portuguesa e brasileira, o que confere ao volume uma sólida perspectiva que antecipa, "per tanti versi, nuovi indirizzi del comparatismo" (p. 91).

E também a propósito das relações culturais entre a Itália e Portugal, é de salientar o estudo de Manuel Ferro (pp. 102-113) sobre a presença de Manzoni em Portugal, partindo da análise anterior de G. C. Rossi; e a intervenção da malograda lusitanista Carmen M. Radulet (pp. 115-121), que vai para além da análise de Storia della letteratura portoghese (1953), citada no título, debruçando-se igualmente sobre Teatro portoghese e brasiliano (1956) e sobre La civiltà portoghese. Profilo storico e storico-letterario (1975), o que a leva a considerar o autor destas grandes obras como "divulgatore ad alto livello" das culturas lusófonas em Itália. A este respeito, é sem dúvida obrigatório referir o estudo de Teresa Gil Mendes (pp. 122-128), a qual revela a sensibilidade e o interesse do estudioso relativamente às novas literaturas africanas de língua portuguesa, manifestados já desde 1965, de que são exemplo a recensão a Giro di Boa (Viragem), de Castro Soromenho, ou o texto dedicado ao poeta angolano Geraldo Bessa Víctor, em 1967; e a comunicação de Regina Célia Pereira da Silva (pp. 157-163), que revisita os muitos artigos divulgativos sobre Goa, vista como encruzilhada entre Oriente e Ocidente, objecto de interesse de G. C. Rossi nos anos cinquenta e nos primeiros anos da década de sessenta do séc. XX.

De assinalar são ainda as comunicações de Giuseppe Mea sobre a sua tradução portuguesa de La letteratura italiana e le letterature di lingua portoghese (pp. 96-101); de Teresa Cirillo Sirri e Gerardo Grossi, recordando o director e animador dos Annali - Sezione Romanza do IUON (pp. 129-137); e a minuciosa investigação de $\mathrm{Ma-}$ riagrazia Russo (pp. 138-156) à volta da actividade didáctica e das colaboraçôes jornalísticas de G. C. Rossi, que não limita a recensão de jornais italianos mas também de artigos vários em jornais portugue- 
ses e brasileiros, desenhando um sector que certamente não pertence à bagagem científica do ilustre estudioso mas constitui decerto "un lavoro di semina che qualcun altro, un giorno, raccoglierà" (p. 154).

$\mathrm{Na}$ sua globalidade, as actas remetem eloquentemente, como se depreende, para uma obra plurifacetada e rica de propostas apontando para vários âmbitos de investigação. E a prova, se fosse necessária, está no diálogo que pôde estabelecer, em muitos casos, com posteriores abordagens, como aquelas de que se procurou aqui dar o relevo que sem dúvida merecem. MANUEL G. SIMŌES

Gli Incogniti e l'Europa, a cura di Davide Conrieri, Bologna, I Libri di Emil, 2011.

A Academia dos Incógnitos, de Veneza, foi fundada por Giovanni Francesco Loredano, por volta de 1623. Sob o lema "Ex ignoto notus", da autoria de Guido Casoni, a sua insígnia, desenhada por Francesco Ruschi e Jacopo Piccini, representa o Nilo, cujas nascentes, 'ignoradas' na época, desciam de um monte para fertilizar uma planície, antes de se lançar no Mediterrâneo. Embora a sua in- tensa actividade fosse de carácter humanístico, cultivava uma certa interdisciplinaridade com o campo das ciências e da medicina, e fomentava a produção e a difusão do livro, a leitura e o debate. Reuniu praticamente no seu seio os representantes das várias tendências da cultura do Barroco, mesmo opositores e anticonformistas, a par de outros que promovem e estimulam o sistema cultural dominante. Contam-se, entre os seus membros de maior projecção, figuras como Ferrante Pallavicino, Gian Francesco Biondi, Girolamo Brusoni e Antonio Rocco. O período de maior esplendor da Academia situa-se nas décadas de 30 e 40 de Seiscentos. Da sua produção, é ampla a variedade em termos genológicos: desde romances e novelas, à história, dissertaçōes académicas, poesia lírica, tratados em latim e em vernáculo, todos eles caracterizados pela veia retórica, pela eficácia narrativa e dinâmica de acção; mas também ainda conta com uma intensa actividade musical, de melodramas, e pictórica, dominando em ambas as áreas um certo eclectismo. Grande parte das obras produzidas no seu seio tiveram alcance europeu. Depois de problemas surgidos na segunda metade 